\title{
Myocardial Protection after Whole Body Heat Stress in the Rabbit Is Dependent on Metabolic Substrate and Is Related to the Amount of the Inducible 70-kD Heat Stress Protein
}

\author{
Michael S. Marber, * J. Malcolm Walker, ${ }^{*}$ David S. Latchman, ${ }^{\star}$ and Derek M. Yellon * \\ ${ }^{*}$ The Hatter Institute For Cardiovascular Studies, Division of Cardiology, University College Hospital, London WC1E 6AU; and \\ Division of Molecular Pathology, University College London Medical School, London W1P 6DB, United Kingdom
}

\begin{abstract}
The aims of this study were to examine the effects of whole body heat stress and subsequent stress protein induction on glycolytic metabolism, mitochondrial metabolism, and calcium handling within the heart. The effect of heat stress on glycolytic and mitochondrial pathways was examined by measuring contractile performance in the presence of glucose and pyruvate, respectively. Calcium handling was assessed using force-interval relationships. Right ventricular papillary muscles taken from heat-stressed and control rabbit hearts were superfused with Kreb's solution containing either glucose or pyruvate and rendered hypoxic for $\mathbf{3 0} \mathrm{min}$. After reoxygenation, the greatest recovery of contractile function occurred in the heat-stressed muscles with pyruvate as substrate; there was, however, no difference in the force-interval relationship between the groups. The degree of contractile recovery was related to the content of the inducible $70-\mathrm{kD}$ but not the $65-\mathrm{kD}$, heat stress protein. This study suggests that heat stress enhances the ability of rabbit papillary muscle to use pyruvate, but not glucose, after reoxygenation, and that the differences seen in contractility may be secondary to induction of the $72-\mathrm{kD}$ stress protein. (J. Clin. Invest. 1994. 93:1087-1094.) Key words: glucose • pyruvate $\bullet$ papillary muscle $\bullet$ hypoxia $\bullet$ force-interval
\end{abstract}

\section{Introduction}

When any living cell is exposed to a sublethal elevation of environmental temperature a series of adaptive changes occur that serve to protect that cell from subsequent increases in temperature (1). A group of proteins, known as the heat shock or heat stress proteins, are the only proteins synthesized during such stress and play a pivotal role in providing this protection $(2,3)$. In cardiac tissue a wide variety of insults result in the synthesis of these stress proteins (4-9). Of particular interest is the finding that these proteins are expressed in response to both permanent coronary ligation associated with infarction (10), as well as brief 5 -min coronary ligations resulting in mild stunning

This work was presented in part at the 64th Scientific Session of the American Heart Association (1991. Circulation. 84 [Suppl. II]621).

Address correspondence to Professor Derek Yellon, Division of Cardiology, The Hatter Institute for Cardiovascular Studies, University College Hospital, Gower Street, London WC1E 6AU, England.

Received for publication 18 September 1992 and in revised form 10 September 1993.

J. Clin. Invest.

(c) The American Society for Clinical Investigation, Inc. 0021-9738/94/03/1087/08 \$2.00

Volume 93, March 1994, 1087-1094 with no infarction (11). The finding that ischemia results in stress protein synthesis suggests that these proteins may be involved in the cellular repair process both during and after the ischemic insult. This has prompted us and others to examine whether prestressed myocardial tissue, entering ischemia with a higher stress protein content, is more resistant than tissue that has normal constitutive expression of these proteins (12-16).

Studies using heat to elevate the stress protein content of myocardial tissue at the onset of ischemia have demonstrated both enhanced recovery of contractile function and resistance to infarction after ischemia (12-16). However, it remains uncertain if the observed protection is secondary to stress protein induction or is a nonspecific effect of whole body temperature elevation.

In previous studies no attempt has been made to correlate the myocardial stress protein content within individual hearts, to the degree of observed protection. The advantage of such a comparison is that it would help define the role of stress proteins in the myocardial protection observed after heat stress. The main difficulty with such an approach is that the stress protein content of the tissue needs to be estimated before the onset of a subsequent stress to ensure that the pattern of induction is not perturbed by the experimental conditions $(9,11)$. By using an isolated papillary muscle model we were able to obtain several similar myocardial specimens from each heart. While one such specimen was used for the assessment of contractile function, the remaining specimens could be used for stress protein analysis.

In the rabbit, preserved mitochondrial activity, increased levels of high energy phosphates, diminished enzyme release, as well as enhanced functional recovery have been reported after ischemia/reperfusion of heat stressed hearts (15). Similarly, in the rat, the enhanced functional recovery that follows heat stress is associated with preservation of mitochondrial ultrastructure (12). Heat stress proteins are known to play an important role in mitochondrial protein metabolism and energy production $(17,18)$, and are also implicated in the switch from aerobic to anaerobic metabolism after heat and other stresses (19). Moreover, upon reperfusion a similar metabolic switch occurs in the heart, when the ability to generate ATP by glycolysis is thought to have special prognostic importance (20). However, the relative contribution of mitochondrial and glycolytic pathways to the enhanced postischaemic recovery seen with heat stress is not known. In addition, studies in noncardiac tissue suggest that heat stress proteins are able to influence protein kinase activity (21) as well as bind calmodulin (22), and thereby may indirectly effect the uptake and release of calcium from the sarcoplasmic reticulum. For these reasons changes in myocardial calcium handling may also contribute to the improved functional recovery that follows ischemia in heat-stressed hearts. 
We have attempted to address these issues by comparing the contractile performance of heat-stressed and nonheat stressed myocardium using substrates with differing mitochondrial and glycolytic availabilities, while assessing calcium handling by means of force interval parameters (23).

\section{Methods}

The experimental model. Male New Zealand White rabbits, weighing $1.8-2.5 \mathrm{~kg}$, were anesthetized using pentobarbitone $(40 \mathrm{mg} / \mathrm{kg}$ i.v. $)$. In the heat-stressed group $(n=25)$, rectal temperature was raised to $42^{\circ} \mathrm{C}$ for $15 \mathrm{~min}$ by wrapping the anesthetized rabbit in an electric warming blanket. Identically anesthetized control rabbits $(n=24)$ were wrapped for similar periods without switching the blanket on. After either sham or true heat stress the animals were allowed to recover. The next day, 20-26 $\mathrm{h}$ after the first anesthetic, the animals were reanesthetized with pentobarbitone $(60 \mathrm{mg} / \mathrm{kg})$ and given $500 \mathrm{U}$ of heparin intravenously. The hearts were rapidly removed, washed in oxygenated modified Krebs solution, and the right ventricle was opened by an incision through the pulmonary artery extended to the apex. The thinnest suitable right ventricular papillary muscle was dissected together with a small portion of attached interventricular septum. The chordae tendinae were fixed to a hook in a water-jacketed organ bath using a 6/0 silk suture and the septal end of the muscle was fixed to a force transducer (UCT2; Gould Statham, $\mathrm{OH}$ ) via the ventricular septal wedge. The remaining papillary muscles and adjoining portions of right ventricular tissue were frozen in liquid nitrogen for stress protein analysis.

Papillary muscle dissection and perfusion was performed in oxygenated modified Krebs solution with the following composition: $118.5 \mathrm{mM} \mathrm{NaCl}, 24.8 \mathrm{mM} \mathrm{NaHCO}_{3}, 4.8 \mathrm{mM} \mathrm{KCl}, 1.2 \mathrm{mM} \mathrm{KH}_{2} \mathrm{PO}_{4}$, $2.0 \mathrm{mM} \mathrm{CaCl}_{2}, 1.4 \mathrm{mM} \mathrm{MgSO}_{4}$. To this was added either $15 \mathrm{mM}$ glucose or $10 \mathrm{mM}$ sodium pyruvate, (sodium pyruvate from Sigma Chemical Co., St. Louis, MO; all other reagents were ANALAR grade from BDH Chemicals, Poole, England). During hypoxia when the perfusate contained no substrate, $10 \mathrm{mM}$ choline chloride was substituted for either glucose or pyruvate to maintain the osmolarity. Solutions were continuously bubbled with either $95 \%$ oxygen plus 5\% carbon dioxide or $95 \%$ nitrogen plus $5 \%$ carbon dioxide, to provide a pH in the organ bath of 7.35-7.45 during the entire procedure. The corresponding oxygen tensions for these gas mixtures in the bath effluent were $50.5-60.2$ and $<6.0 \mathrm{kPa}$, respectively. The organ bath volume was 4 $\mathrm{ml}$ and perfusate flow was set at $8 \mathrm{ml} / \mathrm{min}$ throughout. The temperature was kept at $37 \pm 0.2^{\circ} \mathrm{C}$ by water circulation through jackets surrounding the organ bath and preorgan bath heat exchanger (C-85a Circulator; Techne, Cambridge, UK). Temperature and $\mathrm{pH}$ were measured continuously in the organ bath while $\mathrm{O}_{2}$ and $\mathrm{CO}_{2}$ tensions were monitored intermittently in the organ bath effluent (ABL2 automated blood gas analyzer; Radiometer, Copenhagen, Denmark).

Papillary muscle stimulation protocol and data acquisition. $30 \mathrm{~min}$ after the papillary muscles were fixed in the organ bath they were stretched to a length developing $90 \%$ of maximal active force and the pacing threshold determined. This was followed by a further 30 -min stabilization period. Throughout this time the stimulation rate was maintained at $1 \mathrm{~Hz}$.

Papillary muscles were field stimulated via parallel flattened platinum electrodes using an isolated stimulator (DS2; Digitimer, Hertfordshire, England) triggered by a computerized clock, the pulse amplitude being set at twice threshold with a fixed pulse duration of $2 \mathrm{~ms}$. Tension envelopes were amplified (NL 107; Digitimer), recorded on paper at slow paper speed $(5 \mathrm{~mm} / \mathrm{min})(\mathrm{RS} 3400$ chart recorder; Gould Statham), and simultaneously digitized at $250 \mathrm{~Hz}$ for on-line analysis.

Papillary muscles were stimulated at $1 \mathrm{~Hz}$, apart from baseline, and $0,30,60$, and $90 \mathrm{~min}$ after reoxygenation, when an assessment of force generation in response to extrasystolic beats was performed. Each of these assessments was identical and consisted of a single extrasystolic beat with an initial coupling interval of $200 \mathrm{~ms}$ to the preceding beat. Every 12 beats this interval was increased by $25 \mathrm{~ms}$, until the coupling interval reached $800 \mathrm{~ms}$, the increment then being set at $100 \mathrm{~ms}$ until the coupling interval reached $1,000 \mathrm{~ms}$, and finally the increment was set at $500 \mathrm{~ms}$ until the extrasystolic beat followed the preceding beat by $10,000 \mathrm{~ms}$, concluding the protocol. The force envelope of: $(a)$ the steady state beat immediately preceding the extrasystolic beat, $(b)$ the extrasystolic beat, and $(c)$ the beat following the extrasystolic beat (the postextrasystolic beat) were recorded digitally for subsequent analysis. This entire force interval protocol was recorded over a 15 -min period. The 44 digitized steady state beats recorded during this protocol were averaged to calculate means and standard errors for resting force, developed force, maximum rate of rise of force, maximum rate of fall of force, time to peak tension, and time to $90 \%$ relaxation.

The force developed by the extrasystolic and postextrasystolic beats was normalized by dividing by the force developed by the preceding steady state beat. Normalized beat force was recorded at each extrasystolic interval, these measurements were then collated for each of the four substrate groups to derive force-interval curves comprising of data from 12 individual experiments. The relationship of normalized, extrasystolic, and postextraextrasystolic beats was then plotted against extrasystolic interval.

Timing of changes in papillary muscle superfusion. After the 75min stabilization period, (60 min plus 15 -min force-interval assessment), muscles were rendered hypoxic and deprived of metabolic substrate. Organ bath flow during this 30 -min period was maintained with Krebs buffer bubbled with $95 \%$ nitrogen and 5\% carbon dioxide in which the glucose or pyruvate had been replaced with choline chloride. This 30-min period of hypoxia was followed by reintroduction of oxygen and substrate for a further $90 \mathrm{~min}$. The substrate present during baseline stabilization was either pyruvate or glucose; the same substrate was returned after reoxygenation. The period of hypoxia without substrate resulted in contracture and complete loss of developed force in all groups. Muscle activity during high flow hypoxia was measured, using a digitizing tablet (Summa Sketch II; Summa Graphics, CT), by tracing the area of developed force for the 30-min hypoxic period recorded at slow paper speed $(5 \mathrm{~mm} / \mathrm{min})$. Muscle force during hypoxia was expressed as a percentage of force developed during the stabilization period.

After $90 \mathrm{~min}$ of reoxygenation the papillary muscle relaxed (unloaded) length and diameter were measured using a stage-mounted graticule (Gradicules Ltd., Kent, England), and muscles were then blotted dry and weighed.

Heat stress protein assessment. Right ventricular papillary muscles, remaining after the chosen sister papillary muscle had been successfully suspended in the organ bath, were frozen in liquid nitrogen.

At a later date myocardial specimens were crushed and homogenised in $2 \times$ concentrated SDS-PAGE sample buffer ( $20 \%$ glycerol and $6 \%$ SDS in $0.12 \mathrm{M}$ Tris at $\mathrm{pH} 6.8$ ), protein concentrations were estimated using the BCA reagent (Pierce, Rockford, IL), and equalized by further addition of sample buffer where necessary, and 2-mercaptoethanol at a final concentration of $10 \%$ was added before boiling. Samples were then centrifuged and stored at $-70^{\circ} \mathrm{C}$. Subsequently samples were thawed, recentrifuged, and volumes pipetted to allow loading of $\sim 30$ $\mu \mathrm{g}$ of total protein per lane of slab gel.

Proteins were separated by SDS-PAGE on $0.8-\mathrm{mm}$ thick, $12.5 \%$ acrylamide gels according to Laemmli (24). Two identically loaded gels were prepared, with 10 samples from heat stressed hearts and 4 samples from control hearts. In both these groups the sister papillary muscles were subsequently superfused with pyruvate. The proteins on one gel were transferred to nitrocellulose by Western blotting. The other identical gel was stained with Coomassie Brilliant blue (R250; BDH Chemicals) to visualize protein. It was necessary to confirm equivalency of protein loading directly because the BCA reagent (Pierce) cannot be used in the presence of mercaptoethanol. Hence, although protein concentrations were equalized between the samples on the basis of the Pierce reagent, the intervening boiling and centrifugation steps necessitated rechecking by direct Coomassie visualization.

Protein transfer from SDS-PAGE gel to nitrocellulose was confirmed by Coomassie staining of the gel. After transfer the nitrocellu- 


\begin{tabular}{lcccc}
\hline & $\begin{array}{c}\text { Control } \\
\text { pyruvate }\end{array}$ & $\begin{array}{c}\text { Heat stress } \\
\text { pyruvate }\end{array}$ & $\begin{array}{c}\text { Control } \\
\text { glucose }\end{array}$ & $\begin{array}{c}\text { Heat stress } \\
\text { glucose }\end{array}$ \\
\hline Unloaded diameter $(m m)^{*}$ & $0.87 \pm 0.04$ & $0.87 \pm 0.05$ & $0.89 \pm 0.06$ & $1.00 \pm 0.07$ \\
Developed force $(g)^{\ddagger}$ & $0.74 \pm 0.09$ & $0.64 \pm 0.09$ & $0.64 \pm 0.10$ & $0.79 \pm 0.11$ \\
Resting force $(g)$ & $0.14 \pm 0.02$ & $0.18 \pm 0.03$ & $0.10 \pm 0.04$ & $0.17 \pm 0.04$ \\
Time to peak force $(m S)$ & $106.3 \pm 2.6$ & $94.4 \pm 4.4$ & $103.9 \pm 4.4$ & $97.8 \pm 4.1$ \\
Time to 90\% relaxation $(m S)$ & $193.4 \pm 5.8$ & $183.2 \pm 9.5$ & $186.2 \pm 6.1$ & $174.8 \pm 6.6$ \\
Maximum rate of contraction $(g / s)$ & $13.3 \pm 1.6$ & $13.1 \pm 1.6$ & $12.6 \pm 2.0$ & $15.4 \pm 2.2$ \\
Maximum rate of relaxation $(g / s)$ & $11.1 \pm 1.4$ & $10.5 \pm 1.2$ & $11.8 \pm 1.7$ & $15.2 \pm 2.0$ \\
\hline
\end{tabular}

* Papillary muscle relaxed (unloaded diameter) was determined at the end of the experimental protocol. ${ }^{\ddagger}$ Developed force is calculated as resting force subtracted from peak force. All other measurements were made after a 60 -min stabilization period in either Kreb's solution containing pyruvate or glucose. Whole body heat stress was performed under anesthesia $24 \mathrm{~h}$ before papillary muscles were harvested; control muscles were obtained from rabbits treated with anesthetic alone. $n=12$ for each group.

lose filters were incubated with mouse monoclonal antisera crossreactive to the inducible 70-kD heat shock protein (hsp72)(Stressgen, Sidney, Canada) at 1:1,000 dilution. Second antibody was horseradish peroxidase-conjugated rabbit anti-mouse IgG (Dakopatts, Glostrup, Denmark) at 1:1,000 dilution. The filter was developed using enhanced chemiluminescence (ECL) detection (Amersham, Bucks, UK) and exposed to $\mathrm{x}$-ray film for the appropriate time.

An identical gel was prepared and underwent Western blotting as above, the nitrocellulose filter being exposed to mouse monoclonal antisera raised against human heat shock protein $65(25)(\mathrm{hsp} 65)$ at 1:2,000 dilution. Subsequent treatment was as above with second antibody at $1: 2,000$ dilution.

The relative levels of hsp 72 and hsp 65 were determined using densitometry ( 620 video densitometer with analyst 2 version 3.1 software; Bio-Rad, Hemel, Hempstead, UK), normalizing to the actin band on the Coomassie-stained gel. This procedure adjusts for slight variations in protein loading between samples (26).

Statistical analysis. Results are expressed as means with standard errors determined by conventional methods. Statistical analysis was performed using the Student's two-tailed unpaired $t$ test for single comparisons between heat stress and corresponding control groups. When multiple comparisons were necessary they were performed by analysis of variance (ANOVA) followed by Fisher's protected least significant difference method (27). The Spearman rank correlation method was used to test for significant associations between variables (27). A probability value of $<5 \%$ was considered significant.

\section{Results}

49 papillary muscles from 49 rabbits ( 25 heat stressed and 24 controls) were used in this study and allocated to 4 groups. Group 1 was control pyruvate $(n=12)$, in which papillary muscles from control rabbits were superfused with pyruvate as substrate. Group 2 was heat stress pyruvate $(n=12)$, in which rabbits were heat stressed and the papillary muscles superfused with pyruvate as substrate. Group 3 was control glucose ( $n$ $=12$ ), in which rabbits were controls and papillary muscles were superfused with glucose as substrate. Group 4 was heat stress glucose $(n=13)$, in which rabbits were heat stressed and papillary muscles superfused with glucose as substrate. There was one exclusion from the heat stress glucose group as a result of spontaneous force development after high flow hypoxia. Each group therefore contained 12 papillary muscles. Although three papillary muscles, one from each of the heatstressed pyruvate, control glucose, and control pyruvate groups, suddenly failed to contract secondary to a rise in pacing threshold during the late hypoxic period, they were still included in the final analysis.

Contractility is enhanced by heat stress with pyruvate as substrate. The baseline characteristics of the papillary muscles before high flow hypoxia without substrate were similar in all groups ( Table I). Prior heat stress or choice of substrate did not influence the resting or developed force, the maximum rate of rise or fall of force, the time to peak force, or the time to $90 \%$ relaxation ( Table I).

Individual papillary muscle responses to high flow hypoxia were variable with some muscles increasing their developed force above that of baseline during the early hypoxic period. During hypoxia developed force appeared better sustained in the heat-stressed papillary muscles. The total developed force during hypoxia as a percentage of developed force over the same time period of oxygenation revealed that with either pyruvate or glucose as substrate, the heat stress muscles developed more force than their respective controls (heat stress pyruvate,

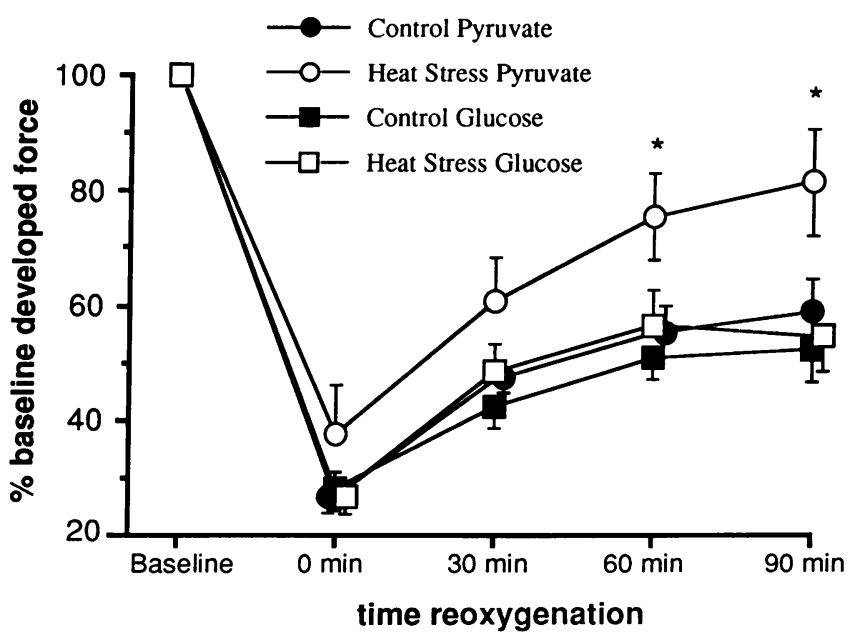

Figure 1. Papillary muscle contractile recovery after $30 \mathrm{~min}$ of hypoxia. For each papillary muscle the amplitude of the force envelope at each time point is expressed as a percentage of the force developed at baseline. Developed force is resting force subtracted from peak force. $n=12$ for each group at each time point. Bars represent SEM. *Significant difference between the heat stress pyruvate group and the other three groups by ANOVA $(P<0.05)$. 
$28.8 \pm 3.8 \%$ vs. control pyruvate, $17.8 \pm 2.2 \% ; P<0.05$; and heat stress glucose, $42.8 \pm 4.4 \%$ vs. control glucose, $27.7 \pm 4.17 ; P$ $<0.05$ ).

Fig. 1 shows that after reoxygenation and reintroduction of substrate the developed force was similar in all groups, however, by $60 \mathrm{~min}$ of reoxygenation the developed force appeared greatest in the heat stress group when pyruvate was used as substrate $(P<0.05$; heat stress pyruvate vs. all other groups by ANOVA). This difference was maintained through to the end of the reoxygenation period (Fig. 1).

The maximum rates of rise and fall in developed force, as well as time to peak tension and $90 \%$ relaxation, followed a broadly similar pattern to those observed for developed force. The heat stress pyruvate group exhibited the most complete return to baseline values $(P=\mathrm{NS})$, while between the control groups a trend was seen in favor of pyruvate as substrate (data not shown ).

In summary, the results indicate that the protection against hypoxia and reoxygenation seen after heat stress is most

A

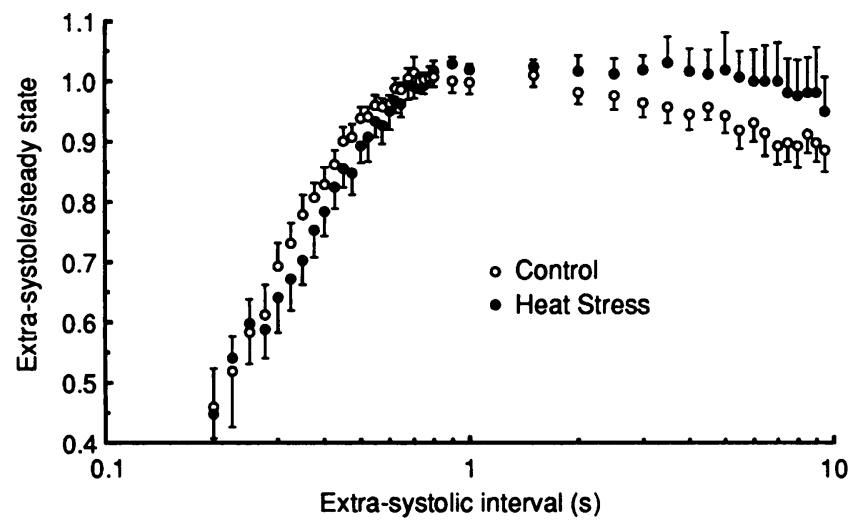

B

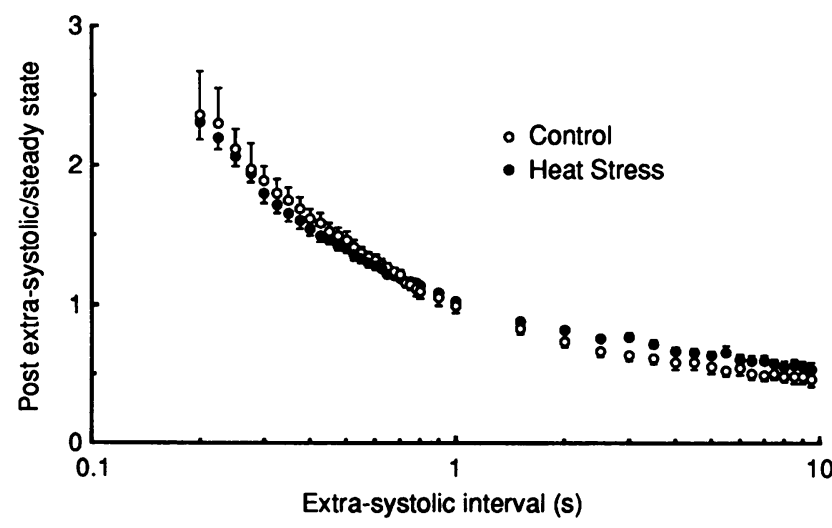

Figure 2. $(A)$ The restitution of the extrasystolic beat at $90 \mathrm{~min}$ of reoxygenation in the heat stress and control pyruvate groups. (B) The decay of postextrasystolic potentiation at $90 \mathrm{~min}$ of reoxygenation in the heat stress and control pyruvate groups. For each papillary muscle the amplitude of the force envelope at each extrasystolic interval is expressed as a ratio of the preceding steady state beat. The data were derived from 12 heat stress pyruvate and 12 control pyruvate muscles. No significant difference exists between control and heat stress groups at any extrasystolic interval.
A

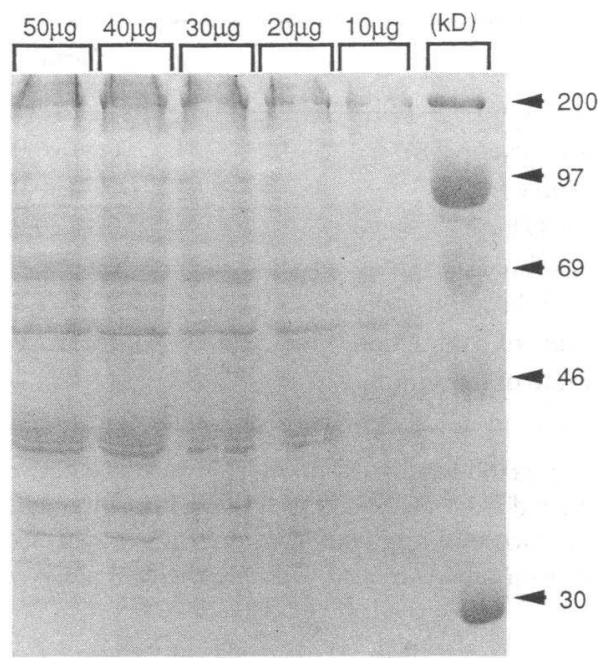

B

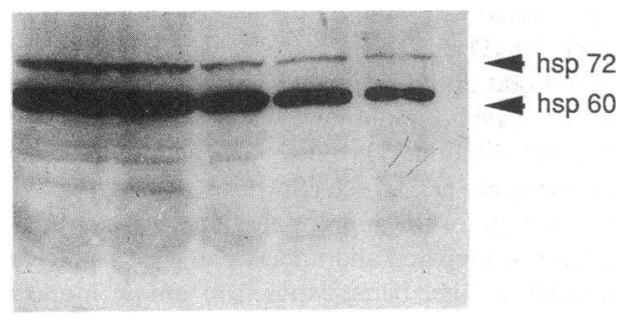

Figure 3. Coomassie staining $(A)$ and immunoreactivity of 65 - and 72-kD stress proteins $(B)$ with increasing protein loading. $(A)$ Pattern of Coomassie staining when increasing amounts of protein are loaded per lane of SDS-PAGE gel. The loading increases from $\sim 10$ to 50 $\mu \mathrm{g}$, from right to left. $(B)$ Appearance of a Western blot prepared in an identical fashion to the Coomassie-stained gel, but probed simultaneously with antibodies against the $65-$ and $72-\mathrm{kD}$ stress proteins. The effect that increasing protein loading has on stress protein immunoreactivity can clearly be seen. The samples used to load the SDS-PAGE gel were prepared from a heat-stressed heart.

marked when pyruvate is used as substrate both before and after hypoxia.

The force-interval relationship remains unchanged. When the force-interval relationships between control and heatstressed pyruvate groups were examined at $90 \mathrm{~min}$ of reoxygenation (Fig. 2), there was no significant separation of data points and the relationships appeared similar. The data comprising these relationships were collected at a time point when there was a significant difference in the developed force of the steady state beats between control and heat-stressed groups with pyruvate (Fig. 1). Similarly, the force-interval relationships did not differ between papillary muscles from heatstressed and control hearts perfused with glucose (data not shown).

The inducible 70-kD heat stress protein (hsp72) is associated with contractile recovery. To compare papillary muscle stress protein content with the posthypoxic contractile recovery of sister papillary muscles, densitometric assessments of Western blots and Coomassie-stained gels were undertaken. Densitometry performed in this fashion showed a linear response to protein loading for both stress protein bands and the actin band on Coomassie-stained gels (See Figs. 3 and 4).

Fig. 5 shows the Coomassie staining pattern of an SDSPAGE gel loaded with the same sample volumes and in the 

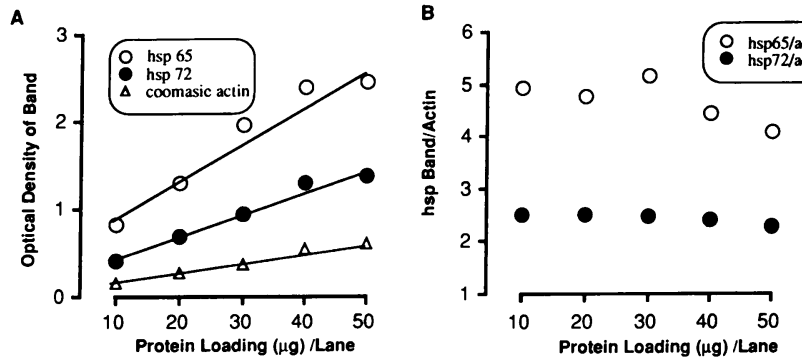

Figure 4. Densitometric assessment of Coomassie actin band and 65and $72-\mathrm{kD}$ stress protein bands with varying protein loading. The data for the figure above were taken from three SDS-PAGE gels loaded in an identical fashion to those shown in Fig. 3, but Coomassie stained or blotted and probed separately with antibodies against the 65- and 72-kD stress proteins. $(A)$ Coomassie actin density, as well as $65-$ and $72-\mathrm{kD}$ stress protein band density, are linearly related to protein loading. $(B)$ Values for stress protein band density are divided by the Coomassie actin band density for each lane. The resultant ratio is independent of protein loading in the range used for the preparation of these blots ( $10-50 \mu \mathrm{g})$.

same order as those used to prepare the Western blots shown in Figs. 6 and 8. The density of Coomassie staining is similar between lanes, indicating that approximately equivalent amounts of protein have been loaded in each lane.

Fig. 6 shows that the basal expression of the $70-\mathrm{kD}$ protein was seen in all control specimens. However, prior heat stress resulted in a variable increase in stress protein content. When blots were examined densitometrically there was an approximate fourfold increase in the content of hsp72 $24 \mathrm{~h}$ after heat stress (heat stress, $6.2 \pm 0.7$ vs. control, $1.7 \pm 0.3 \mathrm{U} ; P=0.003$ ).

When the stress protein content of papillary muscles harvested from heat-stressed hearts was compared to the contractile performance of sister papillary muscles superfused with pyruvate, a significant correlation was found $\left(R^{2}=0.56, P\right.$

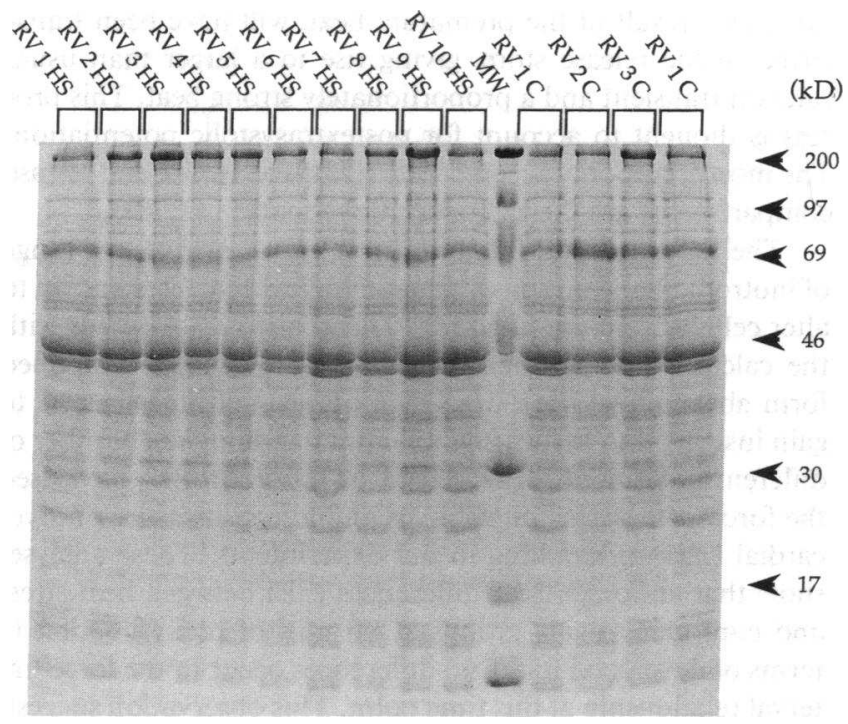

Figure 5. The appearance of a Coomassie-stained SDS-PAGE gel loaded in an identical fashion to those used to prepare Figs. 6 and 7. The Coomassie staining pattern is even across the lanes, suggesting near equivalency of protein loading.

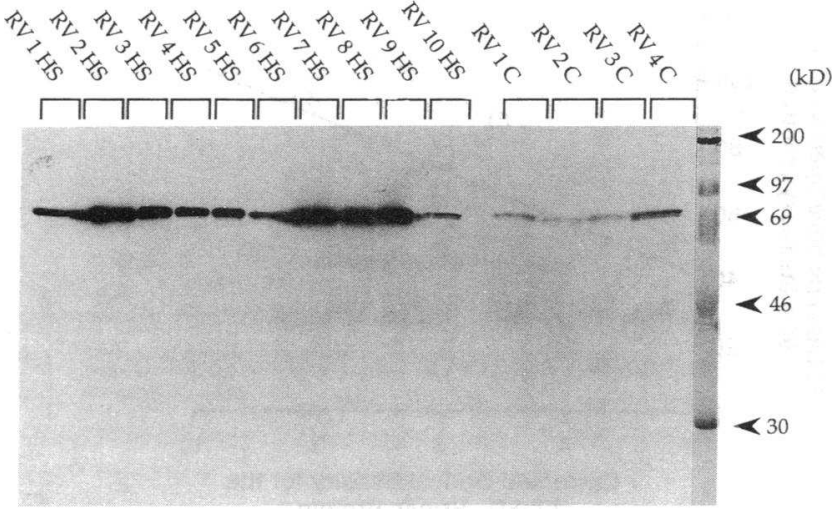

Figure 6. Western blot analysis of right ventricular papillary muscles probed with a monoclonal antibody directed against the inducible 70-kD stress protein (hsp72). The samples on the left hand side of the blot $(R V 1 H S$ to $R V 10 H S)$ are papillary muscles from heatstressed hearts. Sister papillary muscles were subsequently perfused with pyruvate. The samples on the right hand side of the blot $(R V$ $1 C$ to $R V 4 C$ ) are from control hearts. Sister papillary muscles were also subsequently superfused with pyruvate.

$=0.01)$. This indicates that those papillary muscles with a high stress protein content tended to be those muscles with the greatest resistance to hypoxia and reoxygenation (Fig. 7).

The 65-kD heat stress protein ( $h s p 65$ ) is not associated with contractile recovery. In contrast to hsp 72 , the papillary muscle content of hsp65 was not markedly elevated $24 \mathrm{~h}$ after heat stress (Fig. 8). When control and heat stress samples were compared densitometrically the $65-\mathrm{kD}$ protein was raised only $\sim 1$.5-fold after heat stress (heat stress, $4.0 \pm 0.41$ vs. control, $2.9 \pm 0.28 \mathrm{U} ; P=0.14$ ). In addition, Fig. 9 shows that there was no correlation between papillary muscle $65-\mathrm{kD}$ stress protein content and the resistance of sister papillary muscles to hypoxia and reoxygenation $\left(R^{2}=0.14, P=0.3\right)$.

\section{Discussion}

Prior heat stress has been shown to protect against injury in a number of biological systems (28-30). This study confirms that a similar protection against hypoxia and reoxygenation is seen within rabbit right ventricular papillary muscles. Our findings extend the observations of other investigators, which have shown that prior heat stress is able to limit the injury associated with ischemia and reperfusion of the isolated and in situ heart (12-16).

Papillary muscle contractility and substrate preference. Papillary muscle physical dimensions as well as amplitude and rates of change of developed force were similar in all groups before hypoxia. Differences in subsequent performance are not therefore the result of any chance differences in papillary muscle characteristics between groups. During hypoxia, papillary muscle activity was assessed by integration of the force envelope. The activity of muscles in the heat-stressed groups with either pyruvate or glucose as substrate was greater than in the respective control group. The importance of this observation lies in the fact that contractile activity during hypoxia is inversely related to ultimate recovery upon reoxygenation (31). It would therefore be expected that upon reoxygenation the heat-stressed muscles would recover to a lesser degree than 


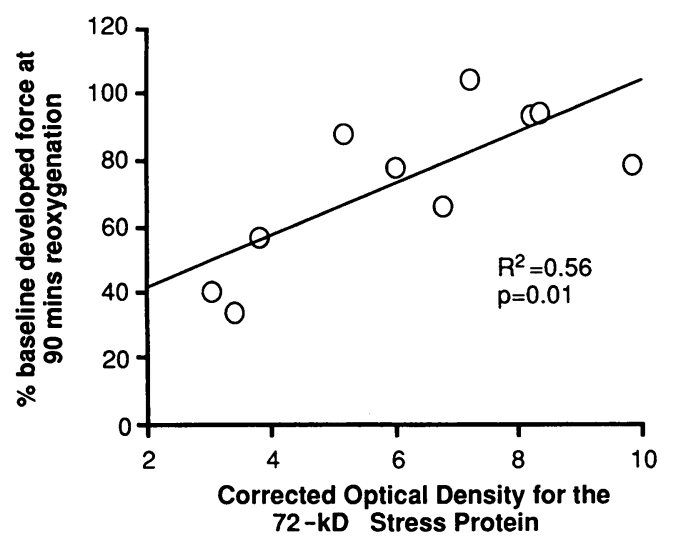

Figure 7. Relationship between papillary muscle content of the inducible 70-kD stress protein (hsp72) and contractile performance. Papillary muscle hsp72 was measured by optical densitometry of samples RV 1 HS to RV $10 \mathrm{HS}$, using the actin band of an identically loaded Coomassie-stained gel to correct for differences in loading between samples (see Fig. 5). The relationship between corrected optical density and papillary muscle contractile activity was determined using the Spearman rank correlation method.

their corresponding controls. In fact with both substrates the opposite was found, and this reversal of the expected findings was most marked with pyruvate. Advantages to reperfusion with pyruvate have been described previously in isolated (nonheat-stressed) hearts $(32,33)$. Hypothetically, if heat stress were to enhance the capabilities of the mitochondria, this would explain the greater functional recovery seen in the heat stress pyruvate group. This benefit may not be apparent with glucose as substrate if damage to the glycolytic pathway were to limit mitochondrial substrate availability to such a degree as to obviate any effect of enhanced mitochondrial function. In addition, the suggestion that the enhanced contractility that follows heat stress is a result of improved mitochondrial function is supported indirectly by the finding that both in vitro mitochondrial function and morphology are preserved after ischemia and reperfusion of heat-stressed hearts $(12,15)$. An alternative explanation for the better recovery in the heat-stressed pyruvate group could be that heat stress enhances pyruvate uptake by the myocyte. This, however, seems less likely as there is no difference in function between the heat stress and control pyruvate groups at baseline.

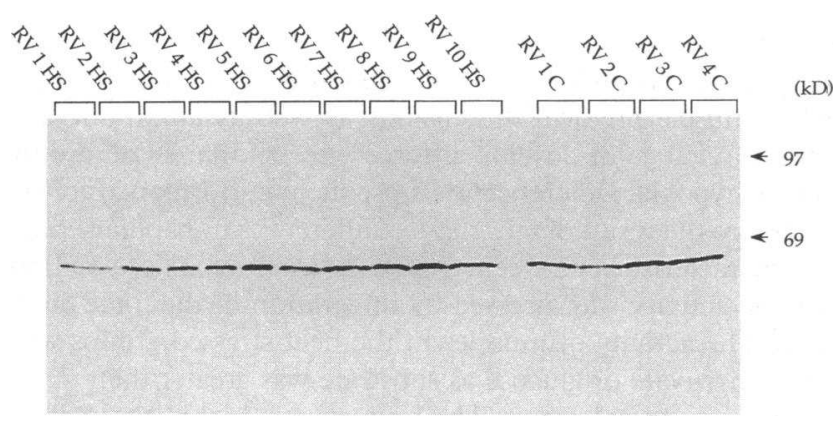

Figure 8 . Western blot analysis of right ventricular papillary muscles probed with a monoclonal antibody directed against the $65-\mathrm{kD}$ stress protein. The lane arrangement and sample loading are identical to Fig. 5.

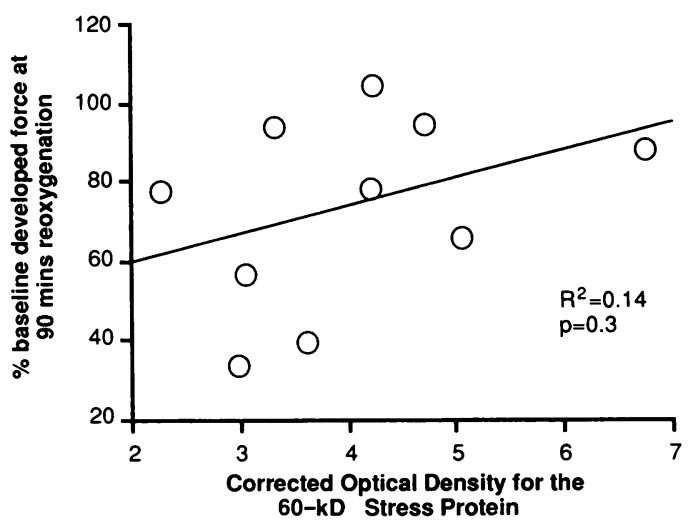

Figure 9. Relationship between the $65-\mathrm{kD}$ stress protein content of papillary muscles and contractile performance. Stress protein content estimation and statistical analysis were identical to Fig. 7.

Force-interval relationships. The changes occurring in the processes of restitution and decay of potentiation after hypoxia are characteristic of the findings seen by other investigators (23). Although the physiological processes that underlie the force-interval relationship are not fully characterized, a number of investigators have demonstrated that developed force after an interposed beat is directly related to the amplitude of the calcium transient (34-37). This observation has prompted authors to propose a model with, in its simplest form, functional uptake and release compartments for calcium (38-40). Generally speaking, these models propose that after a contraction calcium is taken up into the uptake compartment but can only be released from the release compartment. Transfer from uptake to release compartments takes a finite time and probably follows first-order kinetics. Thus, with a premature beat not all the calcium in the uptake compartment will have been transferred to the release compartment, and hence the next calcium transient is small and the resultant beat proportionately weak. This process is thought to account for the mechanical restitution of the extrasystolic beat. On the next (postextrasystolic) beat, the extra "aliquot" of calcium left in the uptake store, as a result of the premature beat, will have been transferred to the release store, giving rise to a larger than usual calcium transient and a proportionately strong beat. This process is thought to account for postextrasystolic potentiation. The most commonly accepted sites for these uptake and release compartments are the sarcoplasmic reticulae $(41,42)$.

The force-interval relationship is very sensitive to a range of inotropic interventions and pathological processes known to alter cellular calcium handling. This sensitivity, together with the calcium compartment models described in a simplified form above, have been used by a number of investigators to gain insights into myocardial calcium handling in a number of different situations $(23,36,37,43,44)$. We similarly have used the force-interval relationship as an indirect measure of myocardial calcium handling in our experiments. These analyses show that although clear differences exist between heat stress and control pyruvate groups at $90 \mathrm{~min}$ of reoxygenation in terms of developed force, no differences occur in the force-interval relationship at this time point. This observation suggests that alterations in papillary muscle calcium handling are not the explanation for the greater developed force in the heatstressed pyruvate group. A more likely interpretation is that a greater amount of viable tissue survived hypoxia/reoxygena- 
tion in the heat-stressed pyruvate group, and that this accounts for the better posthypoxia recovery, while the force-interval relationship is unchanged because the viable myocardium remaining in the heat stress and control groups posthypoxia handle calcium identically.

Stress protein and myocardial function. Although a number of investigators have demonstrated that heat stress limits myocardial injury after ischemia and that similar heat treatment in other animals is associated with an elevation in stress protein content, it is not clear whether these two observations are causally linked. Indeed, Currie et al. and Karmazyn et al. $(12,45)$ have shown that in the rat, endogenous catalase activity is increased after heat stress and that if catalase activity is inhibited, the protection previously noted is lost. The currently favored hypothesis, therefore, is that heat stress increases endogenous myocardial antioxidant defences, which thereby act to limit the injury associated with free radical formation upon reperfusion/reoxygenation.

The results presented in this paper suggest that heat stress may act by preserving mitochondrial function, however, the mechanisms by which stress protein induction or other aspects of heat stress could influence mitochondrial performance are at present tentative. Both the $65-$ and $70-\mathrm{kD}$ family of stress proteins are known to have essential roles in allowing correct unfolding and refolding of nuclear-encoded mitochondrial proteins as they enter the mitochondria from the cytoplasm $(2,18$, $19)$, and so may be able to correctly refold mitochondrial enzymes $(6,46)$ or structural proteins altered during ischemia and reperfusion. In our study the $72-\mathrm{kD}$ stress protein is variably induced after heat stress and correlates with the variable papillary muscle resistance to hypoxia and reoxygenation. Such a correlation provides the first circumstantial evidence for a direct role of this protein in recovery after hypoxia. However, papillary muscles that have responded to heat stress with the highest stress protein response may also respond with the greatest increase in endogenous antioxidant activity. Papillary muscle catalase activity was not measured in this study. The basis for the increase in catalase activity after heat stress is still poorly defined, does not involve a change in the mRNA coding for this enzyme (47), and seems to be species specific (14). Indeed, it has recently been suggested that the heat-induced alteration in catalase activity may be secondary to a direct stress protein interaction, modulating the activity of this enzyme (48). In an attempt to determine if the protection observed in this study was dependent on new protein synthesis, actinomycin and cyclohexamide were administered; both drugs resulted in a $100 \%$ mortality. Similarly, other authors have reported similar problems when attempting 24 -h protein synthesis inhibition in vivo (J. M. Downey, personal communication, and Kuzuya et al. [49]).

Preliminary reports, in keeping with the data presented above, also suggest that hsp 72 is the stress protein most likely to be involved in myocardial protection. For example, the degree of myocardial infarct size reduction in the rat, $24 \mathrm{~h}$ after different severities of whole body heat stress, correlates with myocardial hsp 72 content ( 50 ), while more compelling evidence that myocardial stress proteins are directly protective is provided by the observation that transfecting an embryonal myocyte cell line with human hsp72 causes resistance to simulated ischemia (51).

We also analyzed the papillary muscle samples for the $65-$ $\mathrm{kD}$ stress protein. The $65-\mathrm{kD}$ family of proteins, which are predominantly mitochondrial, are found in association with essential components of the ATP synthesis pathway (19) (namely cytochrome $c$ and F1-ATPase), and are therefore prime candidates for heat stress-mediated mitochondrial protection. When the content of the $65-\mathrm{kD}$ stress protein was measured, it was only mildly elevated $24 \mathrm{~h}$ after heat stress, and there was little variation between samples. No correlation was found between papillary muscle hsp 65 content and contractile recovery.

The results of this study are consistent with the hypothesis that stress proteins are the mediators of the myocardial protection that follows heat stress and indicate for the first time that some families of stress proteins may be more important than others. The hypothesis that stress proteins may directly influence the resistance of the heart to ischemia has major implications, and would suggest that myocardial stress proteins raised by nonthermal means should also be protective. Short episodes of ischemia as may occur in unstable angina have been shown to result in significant stress protein induction over a 24-h period (11), offering the theoretical possibility of a delayed, but perhaps long-lasting, adaptive change that would render the heart resistant to subsequent ischemia. Evidence in support of such a phenomenon exists in neuronal tissue where the stress protein content can be elevated by 2 -min daily episodes of ischemia, a treatment that also seems to increase the neuronal resistance to subsequent more prolonged ischemia (52). Other reports suggest that a similarly delayed protection occurs $24 \mathrm{~h}$ after "classical" ischemic preconditioning of the dog (49) or rabbit (53) heart and also $24 \mathrm{~h}$ after rapid pacing of the rabbit heart (54). The ramifications of these unconfirmed findings are immense and may explain the apparently paradoxical benefits, despite more severe coronary artery disease, of a history of stable angina before myocardial infarction (55).

In conclusion, after $30 \mathrm{~min}$ of hypoxia with substrate deprivation, the recovery of rabbit papillary muscle contractile activity appears greatest in heat-stressed muscles when pyruvate is used as substrate. We postulate this reflects an increase in mitochondrial resistance to hypoxia and reoxygenation after heat stress. The lack of an effect of heat stress on force-interval behavior of muscle suggests that the enhanced contractility occurs independently of alterations in calcium release and reuptake processes within the myocardium. The finding that papillary muscle contractile recovery is closely correlated with the content of the $72-\mathrm{kD}$ stress protein implies that the myocardial protection that follows heat stress may be mediated by an increase in myocardial stress protein content.

\section{Acknowledgments}

We are indebted to the Hatter Foundation for its continued support. The anti-65-kD heat shock protein antibody was a gift from Dr. G. A. Rook (Department of Medical Microbiology, University College London Medical School, London, UK).

M. S. Marber is the recipient of a British Heart Foundation Intermediate Fellowship.

\section{References}

1. Hightower, L. E. 1991. Heat shock, stress proteins, chaperones, and proteotoxicity. Cell. 66:191-197.

2. Smith, B. J., and M. P. Yaffe. 1991. A mutation in the yeast heat-shock factor gene causes temperature-sensitive defects in both mitochondrial protein import and the cell cycle. Mol. Cell. Biol. 11:2647-2655.

3. Li, C. G., and Z. Werb. 1982. Correlation between synthesis of heat shock 
proteins and development of thermotolerance in chinese hamster fibroblasts. Proc. Natl. Acad. Sci. USA. 79:3218-3222.

4. Low, I., T. Fiedrich, and W. Schoeppe. 1989. Synthesis of shock proteins in cultured fetal myocardial cells. Exp. Cell Res. 180:451-459.

5. Moalic, J. M., C. Bauters, D. Himbert, J. Bercovici, C. Mouas, P. Guicheney, M. Baudoin-Legros, L. Rappaport, R. Emanoil-Ravier, V. Mezger, and B. Swynhedauw. 1989. Phenylephrine, vasopressin and angiotensin II as determinants of proto-oncogene and heat shock protein gene expression in adult rat heart and aorta. J. Hypertens. 7:195-201.

6. White, F. P., and S. C. White. 1986. Isoproterenol induced myocardial necrosis is associated with stress protein synthesis in rat heart and thoracic aorta. Cardiovasc. Res. 20:512-515.

7. Chevalier, B., F. Callens, D. Charlemagne, C. Delcayre, A. M. Lompré, L. Lelièvre, J. J. Mercadier, J. M. Moalic, P. Mansier, L. Rappaport, J. L. Samuel, K. Schwartz, and B. Swynghedauw. 1989. Signal and adaptational changes in gene expression during cardiac overload. J. Mol. Cell. Cardiol. 21:71-77.

8. Delcayre, C., S. Samuel, F. Marrotte, M. Best-Belpomme, J. J. Mercadier, and L. Rappaport. 1988. Synthesis of stress proteins in rat cardiac myocytes 2-4 days after imposition of hemodynamic overload. J. Clin. Invest. 82:460-468.

9. Knowlton, A. A., F. R. Eberli, P. Brecher, G. M. Romo, A. Owen, and C. S. Apstein. 1991. A single myocardial stretch or decreased systolic fiber shortening stimulates the expression of heat shock protein 70 in the isolated, erythrocyte-perfused rabbit heart. J. Clin. Invest. 88:2018-2025.

10. Dillmann, W. H., H. Mehta, A. Barrieux, B. D. Guth, W. E. Neeley, and J. Ross. 1986. Ischemia of the dog heart induces the appearance of a cardiac mRNA coding for a protein with migration characteristics similar to Heat-shock/stress protein 71. Circ. Res. 59:110-114.

11. Knowlton, A. A., P. Brecher, and C. S. Apstein. 1991. Rapid expression of heat shock protein in the rabbit after brief cardiac ischemia. J. Clin. Invest. 87:139-147.

12. Currie, R. W., B. M. Ross, and T. A. Davis. 1988. Heat-shock response is associated with enhanced post ischemic ventricular recovery. Circ. Res. 63:543549.

13. Donnelly, T. J., R. E. Sievers, F. L. J. Vissern, W. J. Welch, and C. L. Wolfe. 1992. Heat shock protein induction in rat hearts. A role for improved myocardial salvage after ischemia and reperfusion? Circulation. 85:796-778.

14. Liu, X., R. M. Engelman, I. I. Moraru, D. Lu, D. Nath, J. A. Rousou, J. E. Flack, D. W. Deaton, N. Maulik, and D. K. Das. 1992. Heat shock: A new approach for myocardial preservation in cardiac surgery. Circulation. 86(Suppl. II) :358-363.

15. Yellon, D. M., E. Pasini, A. Cargnoni, M. S. Marber, D. S. Latchman, and R. Ferrari. 1992. The protective role of Heat Stress in the ischaemic and reperfused rabbit myocardium. J. Mol. Cell. Cardiol. 24:342-346.

16. Currie, R. W., R. M. Tanguay, and J. G. Kingma, J. G. 1993. Heat-shock response and limitation of tissue necrosis during occlusion/reperfusion in rabbit hearts. Circulation. 87:963-971.

17. Kang, P., J. Ostermann, J. Shilling, W. Neupert, E. A. Craig, and N. Pfanner. 1990. Requirement for HSP70 in the mitochondrial matrix for translocation and folding of precursor proteins. Nature (Lond.). 348:137-143.

18. Cheng, M. Y., F. U. Hartl, J. Martin, R. A. Pollock, F. Kalousek, W. Neupert, E. M. Hallberg, R. L. Hallberg, and A. L. Horwich. 1989. Mitochondrial heat-shock protein hsp60 is essential for assembly of proteins imported into yeast mitochondria. Nature (Lond.). 337:620-625.

19. Welch, J. W. 1992. Mammalian stress response: cell physiology, structure/function of stress proteins, and implications for medicine and disease. Physiol. Rev. 74:1063-1081.

20. Opie, L. H. 1992. Cardiac metabolism emergence, decline and resurgence. Part I. Cardiovasc. Res. 26:721-733.

21. Rose, D. W., W. J. Welch, G. Kramer, and B. Hardesty. 1989. Possible involvement of the $90-\mathrm{kDa}$ heat shock protein in the regulation of protein synthesis. J. Biol. Chem. 264:6239-6244.

22. Stevenson, M. A., and S. K. Calderwood. 1990. Members of the 70-kilodalton heat shock protein family contain a highly conserved calmodulin binding domain. Mol. Cell. Biol. 10:1234-1238.

23. Seed, W. A., and J. M. Walker. 1988. Relation between beat interval and force of the heartbeat and its clinical implications. Cardiovasc. Res. 22:303-314.

24. Laemmli, U. K. 1970. Cleavage of structural proteins during the assembly of the head of bacteriophage T4. Nature (Lond.). 227:680-685.

25. Sharif, M., J. G. Worrall, J. G., B. Singh, R. S. Gupta, P. M. Lydyard, C. Lambert, J. McCulloch, and G. Rook. 1992. The development of monoclonal antibodies to the human mitochondrial $60 \mathrm{kDa}$ heat shock protein and their use in studying the expression of the protein in rheumatoid arthritis. Arthritis Rheum. 35:1427-1433.

26. Norton, P. M., and D. S. Latchman. 1987. Levels of $90 \mathrm{kDa}$ heat shcck protein and resistance to glutacorticoid-mediated cell killing on a range of human and murine lymphocyte cell lines. J. Steroid Biochem. 33:149-154.

27. Snedecor, G. W., and W. G. Cochran. 1980. Statistical Methods. 7th ed. Iowa State University Press, Ames, IA.

28. Chopp, M., H. Chen, and K.-L. Ho. 1989. Transient hyperthermia protects against subsequent forebrain ischemic cell damage in the rat. Neurology. 39:1396-1398.
29. Barbe, M. F., M. Tytell, D. J. Gower, and W. J. Welch. 1988. Hyperthermia protects against light damage in the retina. Science (Wash. DC). 241:181720.

30. Perdrizet, G. A., H. Kaneko, T. M. Buckley, M. A. Fishman, and R. T. Schweizer. 1990. Heat shock protects against warm ischemic injury. Trans. Proc. 22:460-461.

31. Lewis, M. J., A. C. Grey, and A. H. Henderson. 1979. Determinants of hypoxic contracture in isolated heart muscle preparations. Cardiovasc. Res. 13:86-94.

32. Cavallini, L., M. Valente, and M. P. Rigbello. 1990. The protective action of pyruvate on recovery of ischemic rat heart: comparison with other oxidizable substrates. J. Mol. Cell. Cardiol. 22:143-154.

33. van Bilsen, M., G. J. van der Vusse, L. H. E. H. Snoeckx, T. Arts, W. A. Coumans, P. H. M. Willemsen, and R. S. Reneman. 1988. Effects of pyruvate on post-ischemic myocardial recovery at various workloads. Pfluegers Arch. Eur. J. Physiol. 413:167-175.

34. Weir, W. G., and D. T. Yue. 1986. Intracellular calcium transients underlying the short-term force-interval relationship in ferret ventricular myocardium. J. Physiol. 376:507-530.

35. Allen, D. G., and S. Kurihara. 1980. Calcium transients in mammalian ventricular muscle. Eur. Heart J. 1 (Suppl. A):5-15.

36. Yue, D. T. 1992. Relationship between intracellular free calcium and force with changes of interval. In The Interval Force Relationship of the Heart: Bowditch Revisited. M. I. M. Noble and W. A. Seed, editors. Cambridge University Press, New York, 95-108.

37. Gwathmey, J. K., M. T. Slawsky, R. J. Hajjar, G. M. Briggs, and J. P. Morgan. 1990. Role of intracellular calcium handling in force-interval relationships of human myocardium. J. Clin. Invest. 85:1599-1613.

38. Morad, M., and Y. Goldman. 1973. Excitation-contraction coupling in heart muscle: Membrane control of development of tension. Prog. Biophys. Mol. Biol. 27:257-313.

39. Wohlfart, B. 1979. Relationships between peak force, action potential duration and stimulus interval in rabbit myocardium. Acta Physiol. Scand. 106:395-409.

40. Schouten, V. J., J. K. van Deen, P. de Tombe, and A. A. Verveen. 1987 Force-interval relationship in heart muscle of mammals. A calcium compartment model. Biophys. J. 51:13-26.

41. Benijamali, H. S., W. Gao, B. R. MacIntosh, and H. E. J. D. ter Keurs 1991. Force-Interval relations of twitches and cold contracture in rat cardiac trabeculae effect of ryanodine. Circ. Res. 69:937-947.

42. Fabiato, A., and F. Fabiato. 1977. Calcium release from the sarcoplasmic reticulum. Circ. Res. 40:119-129.

43. Cooper, I. C., and C. H. Fry. 1990. Mechanical restitution in isolated mammalian myocardium; species differences and underlying mechanisms. $J$. Mol. Cell. Cardiol. 22:43-452.

44. Bobet, J., S. E. Howlet, and T. Gordon. 1991. Possible mechanisms underying differences in force production between normal and cardiomyopathic hamster atria. Am. J. Physiol. 261:H1603-H1608.

45. Karmazyn, M., K. Mailer, and R. W. Currie. 1990. Acquisition and decay of heat-shock-enhanced postischemic ventricular recovery. Am. J. Physiol 259:H424-H431.

46. Pauly, D. F., K. A. Kirk, and J. B. McMillin. 1991. Carnitine palmitoyltransferase in cardiac ischemia. A potential site for altered fatty acid metabolism. Circ. Res. 68:1085-1094.

47. Currie, R. W., and R. M. Tanguay. 1991. Analysis of RNA for transcripts for catalase and SP71 in rat hearts after in vivo hyperthermia. Biochem. Cell Biol. 69:375-82

48. Kukreja, R. C., and M. L. Hess. 1992. The oxygen free radical system: from equations through membrane protein interactions to cardiovascular injury and protection. Cardiovasc. Res. 26:641-655

49. Kuzuya, T. S. Hoshida, N. Yamashita, H. Fuiji, H. Oe, M. Hori, T. Kamada, and M. Tada. 1993. Delayed effects of sublethal ischemia on the acquisition of tolerance to ischemia. Circ. Res. 72:1293-1299.

50. Hutter, M. M., R. E. Sievers, and C. L. Wolfe. 1993. Myocardial protection after heat shock pretreatment correlates with the degree of prior stress protein induction (abstract). J. Am. Coll. Cardiol. 21:70A.

51. Mestril, R., S.-H. Chi, R. M. Sayen, and W. H. Dillmann. 1992. Expression of a human heat shock protein in rat heart derived $H 9 \mathrm{c} 2$ cells confers resistance against ischemic injury (abstract). Circulation. 86(Suppl. I):557.

52. Nowak, T. S. 1990. Protein synthesis and heat shock/stress response after ischemia. Cerebrovasc. Brain Metab. Rev. 2:345-366.

53. Marber, M. S., D. S. Latchman, J. M. Walker, and D. M. Yellon. 1993 Cardiac stress protein elevation 24 hours after brief ischemia or heat stress is associated with resistance to myocardial infarction. Circulation. 88:1264-1274.

54. Szekeres, L., J. G. Papp, Z. Szilvassy, E. Udvary, and A. Vegh. 1993. Moderate stress by cardiac pacing may induce both short-term and long-term cardioprotection. Cardiovasc. Res. 27:593-596.

55. Muller, D. W., E. J. Topol, R. M. Califf, K. N. Sigmon, L. Gorman, B. S George, D. J. Kereiakes, K. L. Lee, and S. G. Ellis. 1990. Relationship between antecedent angina pectoris and short-term prognosis after thrombolytic therapy for acute myocardial infarction. Thrombolysis and angiopasty in myocardial infarction (TAMI) study group. Am. Heart J. 119:224-231. 